\title{
HIV leadership programming attendance is associated with PrEP and PEP awareness among young, gay, bisexual, and other men who have sex with men in Vancouver, Canada
}

Kalysha Closson ${ }^{1,2}$, Sarah Chown ${ }^{3}$, Heather L. Armstrong ${ }^{1,4^{*}}$ (D) Lu Wang ${ }^{1}$, Nicanor Bacani ${ }^{1}$, Darren Ho ${ }^{5}$, Jody Jollimore ${ }^{5}$, Gbolahan Olarewaju', David M. Moore ${ }^{1,4}$, Eric A. Roth ${ }^{6}$, Robert S. Hogg ${ }^{1,7}$ and Nathan J. Lachowsky ${ }^{1,8}$

\begin{abstract}
Background: Young gay, bisexual, and other men who have sex with men (YGBM) may have reduced engagement and knowledge of HIV care and biomedical HIV prevention strategies, such as pre-exposure prophylaxis (PrEP), postexposure prophylaxis (PEP), and Treatment as Prevention (TasP), compared with adult GBM. We sought to understand differences in HIV prevention awareness, health care access, and service utilization between youth (16-29years) and adult ( $\geq 30$ year) GBM, as well as factors associated with attendance in HIV leadership programming among YGBM living in the publicly funded PrEP setting of Vancouver, Canada.
\end{abstract}

Methods: Sexually-active GBM were recruited using respondent-driven sampling (RDS) from February 2012 to February 2015. Participants completed an in-person computer-assisted self-interview every 6 months, up to February 2017, with questions on sociodemographic factors, awareness of biomedical HIV prevention strategies, and an HIV treatment optimism-skepticism scale. Participants were asked if they had ever attended either of two HIV-leadership programs designed for YGBM. Both programs involve multiple GBM-led education and social networking sessions operated by community-based organizations in Vancouver. Multivariable Glimmix confounder models assessed differences between youth and adult GBM. Among younger men, bivariate analyses examined factors associated with HIV-leadership program attendance.

Results: Of 698 GBM who enrolled in the longitudinal study, 36.8\% were less than 30 years old at the first study visit. After controlling for gender identification, sexual orientation, HIV status, and income in the past 6 months, younger GBM ( $n=257 / 698)$ had lower awareness of biomedical HIV prevention strategies and less HIV treatment optimism compared with older GBM $(n=441 / 698)$. Among younger GBM who attended HIV-leadership programs $(n=50)$, greater awareness of biomedical HIV prevention strategies and higher HIV treatment optimism were reported, compared with non-attendees.

(Continued on next page)

\footnotetext{
* Correspondence: harmstrong@cfenet.ubc.ca

${ }^{1}$ British Columbia Centre for Excellence in HIV/AIDS, 608-1081 Burrard St,

Vancouver, BC V6Z 1Y6, Canada

${ }^{4}$ Faculty of Medicine, University of British Columbia, 317-2194 Health

Sciences Mall, Vancouver, BC V6T 1Z3, Canada

Full list of author information is available at the end of the article
}

(c) The Author(s). 2019 Open Access This article is distributed under the terms of the Creative Commons Attribution 4.0 International License (http://creativecommons.org/licenses/by/4.0/) which permits unrestricted use, distribution, and reproduction in any medium, provided you give appropriate credit to the original author(s) and the source, provide a link to the Creative Commons license, and indicate if changes were made. The Creative Commons Public Domain Dedication waiver (http://creativecommons.org/publicdomain/zero/1.0/) applies to the data made available in this article, unless otherwise stated. 
(Continued from previous page)

Conclusion: Younger GBM, who are disproportionately affected by the HIV epidemic, are less aware of new prevention technologies than older GBM, but attending peer-based HIV-leadership programs ameliorates agedisparities in HIV-prevention knowledge and treatment optimism.

Keywords: Gay, bisexual, and other men who have sex with men, Youth, Leadership, Health promotion

\section{Background}

Young adulthood is a life stage characterized by self and sexual exploration which can lead to higher incidence of sexually transmitted infections (STIs), including human immunodeficiency virus (HIV), higher substance use, and greater mental health concerns. Today, young gay, bisexual, and other men who have sex with men (YGBM) are initiating sexual activity in an era with increased access to HIV antiretroviral therapy used now for both treatment and prevention. However, YGBM continue to represent a key population in the global HIV epidemic [1]. In Canada, GBM represented $44.1 \%$ of all new infections in 2016, with over half of all new infections among those aged 1529 years old attributed to GBM [2]. Moreover, evidence suggests that HIV incidence may be increasing among younger generations of men [3].

Prior to relatively recent improvements in antiretroviralbased HIV prevention strategies, condom promotion and seroadaptive behavioral strategies were the main HIV prevention mechanisms promoted to and used by GBM [4]. These strategies continue to play a key part in comprehensive HIV prevention strategies, but new HIV transmissions persist [4, 5]. Prevention frameworks, including Coates' 2008 highly active HIV prevention framework [6], acknowledge the need for multiple strategies including: 1) behavioral adaptations such as serosorting, seropositioning, and viral load sorting, 2) antiretroviral treatment for those living with HIV and campaigns like "undetectable equals untransmittable" (U=U) that highlight people with undetectable HIV viral loads cannot transmit the virus, 3) antiretroviral prevention interventions like pre-exposure prophylaxsis (PrEP) and post-exposure prophylaxsis (PEP), and 4) social justice and human rights, such as those that provide protection for all sexual orientations, gender identities, and gender expressions. Collectively, these strategies would reduce HIV transmission among GBM if the options are implemented equitably $[1,6,7]$. Unfortunately, important strides in prevention options are co-occurring against a background of persistent HIV stigma and homophobia [8-10]. Thus, despite increasing visibility of some gay men's lives and greater awareness of the inequities experienced by GBM, frameworks for highly active HIV prevention are rarely adopted within health promotion initiatives. These realities have important implications for GBM in general, and particularly for younger GBM who are initiating their sexual lives in a climate of shifting societal norms and evolving HIV prevention technologies.

In British Columbia, Canada PrEP is currently available at no cost to eligible individuals based on clinical guidelines, one criterion being a score of 10 or greater on the HIV incidence risk index for men who have sex with men (HIRI-MSM); PrEP eligibility favours younger men, as GBM aged between 18 and 28 years receive eight points on the HIRI-MSM tool just due to age [11]. Despite increased diversity in potential HIV prevention and treatment strategies, YGBM may not be receiving adequate comprehensive sexual education and community support to effectively use them. As such, youth advocacy groups have stated that they want sexual education that is standardized, fun, relevant, and delivered by allies who are comfortable talking to young people about sex [12]. Across a number of provinces in Canada, limited information is provided to students regarding diversities in sexual orientation and gender identity [13]. In the classroom, education on sexual practices predominantly discusses penile-vaginal sex, with few opportunities for students to learn and ask questions about other sexual behavior [14]. Poor access to comprehensive sex education that addresses the unique sexual health needs of YGBM, may result in reduced awareness of important components of sexual health, including testing, biomedical prevention strategies including PrEP, and treatment options for STIs and HIV $[15,16]$. Without adequate awareness of the combination prevention options, YGBM will likely continue to be at increased risk of acquiring HIV. In BC, there has been increasing efforts to address school safety with supportive policies; these have found to be effective at improving both the health outcomes of sexual and gender minority youth students, as well as other students [17].

Historically, evidence-based interventions for sexual health among GBM have focused on individual-level behavior change and one example is Mpowerment [18, 19]. Mpowerment is an evidence-based behavioral intervention developed at the University of California-San Francisco in the early 2000s [20]. Since 2012, this program has been implemented in Vancouver by YouthCO, a youth-led community-based organization for youth living with and affected by HIV and Hepatitis C (www.youthco.org/mpowerment). At YouthCO, all programming takes place within the values of anti-oppression. The Mpowerment 
Project leverages social networks to provide accurate, stigma-free information about sexual health to sexually active YGBM. Led by YouthCO staff and a dedicated group of volunteers known as Core Group, MpowermentYVR is continuously adapted to respond to local needs and integrates a highly-active HIV prevention strategy into the programming through sharing information, access to HIV treatment and prevention tools (e.g., condoms, testing), and skills building to help HIV-positive and HIV-negative participants navigate their sexual lives and the myriad of social factors that affect them (e.g, substance use, mental health, and social connection). This program offers alternative social spaces and opportunities to cultivate friendships and community outside of the typically sexualized "gay bar" setting.

Another youth leadership program for YGBM in Vancouver is Totally Outright [21], which is funded by the Public Health Agency of Canada. The program was launched in 2005 by the Community-Based Research Centre, a Vancouver-based non-profit organization working to strengthen health outcomes for GBM [21], and consists of a 40-h leadership course including a series of workshops, a fieldwork assignment, a group project, and social activities which together aim to develop a corps of sex-savvy YGBM who would educate others about highly-active HIV prevention, sexual and mental health as well as emerging concepts like harm reduction, seroadaptive strategies, social justice, and anti-oppression. Applying both peer-based and intergenerational learning has proven to be an effective model and the program continues to run annually in Vancouver, offered by Health Initiative for Men (HIM), and across Canada by other front-line organizations in a variety of cities including Edmonton, Calgary, Winnipeg, Toronto, and Halifax. Both MpowermentYVR and Totally Outright aim to improve the sexual health literacy, knowledge, and awareness of HIV prevention and treatment among YGBM who are disproportionately affected by the epidemic.

Given the disproportionate risk of HIV among YGBM, we sought to understand gaps in HIV prevention uptake by examining differences in HIV prevention awareness, health care access, and service utilization between youth and adult GBM. Additionally, we sought to explore factors associated with participating in these two youth-focused GBM-led HIV leadership programs among YGBM living in Vancouver, Canada. We hypothesized that younger GBM would have less awareness about HIV prevention technologies than older GBM. We further hypothesized that YGBM who participated in an HIV leadership program would have increased awareness of biomedical HIV prevention technologies and more HIV treatment optimism, relative to non-attendees.

\section{Methods}

Study sample

We use an observational study design to address our study aims in order to evaluate the real-world uptake, effectiveness and impact of these programs. Sexually active GBM were recruited into a longitudinal cohort study using respondent-driven sampling (RDS) from February 2012 to February 2015, with follow-up visits occurring every 6 months until February 2017. Details of the study methodology have been previously reported [22]. In brief, GBM were eligible for participation if they identified as a man, including trans men, reported having sex with another man in the past 6 months, were at least 16 years of age, lived within Metro Vancouver, and were able to complete a questionnaire in English. The study office was located in Vancouver's West End, Vancouver's traditional gay neighborhood. At each study visit, participants completed a computer-assisted, self-administered questionnaire on demographics, attitudes, sexual behavior, HIV prevention practices, and community leadership program utilization. The Momentum study employed a nurse that was specifically trained in public health and STI certified practice [23]. At each visit, the nurse administered a brief questionnaire, the HIV and STI testing, and provided referrals to primary care, community services or other resources for any issues that arose.

Participants received a $\$ 50$ honorarium for completing each study visit (or the equivalent value in draw tickets for a larger prize) and an additional $\$ 10$ for each subsequent eligible participant they recruited (to a maximum of six). Written informed consent was obtained from all participants prior to participation. All study activities were approved by the research ethics boards of the University of British Columbia, the University of Victoria, and Simon Fraser University.

\section{Dependent variable}

We examined select differences between young GBM (aged 16-29) and older GBM ( $\geq 30$ years). We chose to compare those under 30 to those 30 and over (time-dependent) to be consistent with past research conducted among YGBM, and to match the Commonwealth definition of youth $[24,25]$.

We further conducted a sub-analysis that included all study participants < 35 years who were asked about participation in two HIV leadership programs (MpowermentYVR and Totally Outright). The wider age range was used to accommodate eligibility in the community programs across the two-year data collection period (2015-2017) and to better capture the duration these programs have been running in Metro Vancouver (e.g. Mpowerment was launched in 20125 years prior to the end of data collection). Questions regarding HIV leadership attendance were added later in the study and thus 
were collected over a two-year study period from 2015 to 2017. Program attendance was measured as a time varying visit-level outcome where participants could report no attendance in one visit but report attendance in a following visit.

\section{Independent variables}

In order to assess differences between younger and older GBM, we examined the association between a number of demographic, sexual behavior, prevention strategies, awareness of biomedical HIV prevention options, and health seeking behaviors with age group (youth vs. adult GBM).

Demographic variables were controlled for in the analyses. These included: gender identity (gender minority, cis male), sexual orientation (gay, bisexual, other), race/ ethnicity (White, Indigenous, Asian, other), lab-confirmed HIV serostatus (negative, positive), formal education (did not complete high school, completed high school), and annual income $(<\$ 30,000$ CAD, $\$ 30,000$ CAD- $\$ 59,999$ CAD, $\geq \$ 60,000$ CAD).

Sexual behavior items included having a current regular partner, number of sexual partners in the past 6 months, and engaging in any escort/sex work in the past 6 months. HIV risk behavior was assessed using a 4-level categorical variable: only condom-protected anal intercourse in the past 6 months (referent) compared with not engaging in anal sex, any condomless anal sex with an opposite or unknown HIV status partner, or condomless anal sex only with same HIV serostatus partners. Participants were asked about five different HIV prevention practices in the past 6 months: consistent condom use, seropositioning (i.e., selecting anal sex position based on HIV status); serosorting (i.e., selective condom non-use with sexual partners with the same HIV status); viral load sorting (i.e., selective condom non-use when the HIV-positive partner is on treatment or has an undetectable viral load); and asking partners their HIV status.

Awareness of HIV prevention strategies was determined by asking participants two items to assess whether or not they had heard of PrEP and PEP (No vs. Yes). Participants' attitudes towards HAART were assessed using Van de Ven's HIV treatment optimism-skepticism scale [26]. Participants responded using a 4-point Likert scale to indicate agreement with 12 statements regarding viral load testing and HIV treatment (e.g., "New HIV treatments will take the worry out of sex"), with higher scores indicating greater treatment optimism (range $=12-48$; study Cronbach alpha $=0.85$ ).

Items related to health care and service utilization asked participants about whether they had been tested for any STIs as well as if they had been diagnosed with any STI in the past 6 months (P6M). Participants were also asked about whether they have a general practitioner (GP) and for those that did, if they had told their GP about their sexual orientation.

\section{Statistical analysis}

Descriptive statistics are presented by age category. Bivariate analyses were performed using Pearson's chi-squared or Fisher's exact test for categorical variables and Wilcoxon rank sum test for continuous variables to examine differences between GBM under 30 compared with those 30 and older.

Unadjusted and adjusted generalized linear mixed models for longitudinal data were used to account for RDS chain and participant (from all visits) clustering in order to assess differences in awareness, access, and service utilization (i.e., having a GP) between younger (18-29 years old) and older GBM $(\geq 30)$. Adjusted models controlled for HIV status, income, gender, and sexual orientation.

Among participants under the age of 35 years who were asked about participating in two HIV leadership programs, unadjusted generalized linear mixed models were used to examine factors associated with ever attended (at any visit) a YGBM HIV prevention leadership program. Statistical interactions were tested to examine whether HIV-status modified the effect of each independent variable on program participation at the univariable level.

\section{Results}

Of 698 GBM who enrolled in the longitudinal study, $36.8 \%$ were less than 30 years old at first visit. Table 1 presents baseline sociodemographic, sexual health attitudes and practices, and sexual behavior characteristics by age group. It should be noted that even though YGBM aged 16-17 were eligible for participation, the youngest participants were 18 years old. The majority of participants were White (75.5\%), with no statistically significant difference in ethnicity breakdown by age group. YGBM were more likely than older GBM to identify as a gender minority $(5.1 \%$ versus $0.7 \% ; p<0.001)$, to identify as a sexual minority other than gay or bisexual (10.5\% versus $3.9 \%, p=0.001)$, to be HIV-negative (95.7\% versus $56.9 \% ; p<0.001)$, to have an annual income $<\$ 30,000$ CAD $(72.0 \%$ versus $54.9 \%,<0.001)$, and to be single (65.8\% versus $57.8 \%)$. In the 6 months prior to the baseline study visit, YGBM were more likely to report using consistent condom use (67.6\% versus $45.6 \%)$ and asking their partner about their HIV status $(65.2 \%$ versus $55.8 \%$, $p=0.015)$ as HIV prevention strategies compared with older GBM. YGBM were less likely to report any condomless anal sex with serodiscordant or unknown status partners $(32.0 \%$ vs. $44.4 \%, p=0.002)$, and less likely to use seropositioning $(20.7 \%$ versus $34.4 \% ; p<0.001)$ and viral load sorting $(7.4 \%$ versus $25.7 \%, p<0.001)$ as HIV prevention strategies. YGBM were less likely to be aware of PrEP $(14.4 \%$ versus $29.4 \%, p<0.001)$ and they had 
Table 1 Baseline sociodemographic, sexual health attitudes and practices, and sexual behavior characteristics between youth (16-29) and adult ( $\geq 30)$ GBM in Vancouver, BC $(n=698)$

\begin{tabular}{llll}
\hline & Younger & Older & P-value \\
$(n=257)$ & $(n=441)$ & \\
$\mathrm{N}(\%)$ & $\mathrm{N}(\%)$ & \\
& &
\end{tabular}

Demographics

Gender Identity

Male

Transman/Intersex

Sexual Orientation

Gay

Bisexual

Other

Ethnicity

White

Indigenous

Asian

Other

HIV Status

Negative

Positive

Formal Education

Did not complete high school

Completed high school

Annual Income

$$
\begin{aligned}
& <\$ 30,000 \\
& \$ 30,000-\$ 59,999
\end{aligned}
$$

$\$ 60,000$ or more

Relationship Status

$$
\text { Single }
$$

Behavior

Number of Male Sex Partners, P6M: median, Q1-Q3

Sexual Risk, P6M

$$
\text { No anal sex }
$$

Only condom-protected anal intercourse

Any condomless anal sex, but only seroconcordant

Any serodiscordant condomless anal sex

Any Escort/Sex Work

$$
\text { No }
$$

Yes, in P6M

Yes, but not in P6M

$\mathrm{N}(9)$

$\begin{array}{ll}244(94.9) & 438(99.3) \\ 13(5.1) & 3(0.7) \\ 216(84.1) & 384(87.1) \\ 14(5.5) & 40(9.1) \\ 27(10.5) & 17(3.9) \\ & \\ 197(76.7) & 330(74.8) \\ 30(11.7) & 39(8.8) \\ 8(3.1) & 32(7.3) \\ 22(8.6) & 40(9.1)\end{array}$

$\begin{array}{lll}246(95.7) & 251(56.9) & \\ 11(4.3) & 190(43.1) & \\ & & 0.001\end{array}$

$17(6.6) \quad 34(7.7)$

$240(93.4) \quad 407(92.3)$

$185(72.0) \quad 242(54.9)$

$61(23.7) \quad 126(28.6)$

$11(4.3) \quad 73(16.6)$

169 (65.8) $255(57.8)$

$88(34.2) \quad 186(42.2)$

0.098

$<0.001$

$5(3-11) \quad 5(2-19)$

0.340

0.002

$27(10.7) \quad 55(12.8)$

$69(27.3) \quad 78(18.1)$

$76(30.0) \quad 106(24.7)$

$81(32.0) \quad 191(44.4)$

$223(86.8) \quad 350(79.4)$

$20(7.8) \quad 24(5.4)$
$<0.001$

$14(5.5) \quad 67(15.2)$
Table 1 Baseline sociodemographic, sexual health attitudes and practices, and sexual behavior characteristics between youth (16-29) and adult ( $\geq 30)$ GBM in Vancouver, BC $(n=698)$ (Continued)

\begin{tabular}{l}
\hline \\
Prevention Practice, P6M: Consistent \\
Condom Use \\
No \\
Yes \\
Prevention Practice, P6M: \\
Seropositioning \\
No \\
Yes \\
Prevention Practice, P6M: \\
Serosorting \\
No \\
Yes \\
Prevention Practice, P6M: Viral Load \\
Sorting \\
No \\
Yes
\end{tabular}

Prevention Practice, P6M: Ask Partner Their HIV Status

$\begin{array}{lll}\begin{array}{l}\text { Younger } \\ (n=257)\end{array} & \begin{array}{l}\text { Older } \\ (n=441)\end{array} & P \text {-value } \\ \mathrm{N}(\%) & \mathrm{N}(\%) & \end{array}$

$\mathrm{N}(\%) \quad \mathrm{N}(\%)$

$<0.001$

$83(32.4) \quad 239(54.4)$

$173(67.6) \quad 200(45.6)$

$203(79.3) \quad 288(65.6)$

$53(20.7) \quad 151(34.4)$

0.384

$155(60.5) \quad 251(57.2)$

$101(39.5) \quad 188(42.8)$

$<0.001$

$237(92.6) \quad 326(74.3)$

$19(7.4) \quad 113(25.7)$

0.015

$$
\text { No }
$$

Yes

89 (34.8) $194(44.2)$

$167(65.2) \quad 245(55.8)$

Awareness and Attitudes

Heard of TasP

0.009

No

139 (54.1) 193 (43.9)

Yes

$118(45.9) \quad 247(56.1)$

Heard of PrEP

No

Yes

178 (85.6) $243(70.6)$

$30(14.4) \quad 101(29.4)$

Heard of nPEP

No

$100(48.1) \quad 139(40.4)$

Yes

$108(51.9) \quad 205(59.6)$

HIV Treatment Optimism Scale Score median, Q1-Q3

$24(21-27) \quad 26(21-30)$

$<0.001$

Health Care

Any STI Testing, P6M

0.205

No

$98(43.0) \quad 149(37.8)$

Yes

$130(57.0) \quad 245(62.2)$

Any STI Diagnosis, P6M

0.774

No

$221(88.0) \quad 364(88.8)$

Yes

$30(12.0) \quad 46(11.2)$

Have a General Practitioner (GP)

$$
\text { No }
$$

Yes
$116(45.7) \quad 355(81.2)$

$<0.001$

138 (54.3) $82(18.8)$ 
Table 1 Baseline sociodemographic, sexual health attitudes and practices, and sexual behavior characteristics between youth (16-29) and adult ( $\geq 30)$ GBM in Vancouver, BC $(n=698)$ (Continued)

\begin{tabular}{llll}
\hline & $\begin{array}{l}\text { Younger } \\
(n=257) \\
\mathrm{N}(\%)\end{array}$ & $\begin{array}{l}\text { Older } \\
(n=441) \\
\mathrm{N}(\%)\end{array}$ & P-value \\
\hline $\begin{array}{llll}\text { Told GP about sexual orientation } \\
\text { "out" }\end{array}$ & & & $<0.001$ \\
No & $38(32.8)$ & $31(8.7)$ & \\
Yes & $78(67.2)$ & $324(91.3)$ &
\end{tabular}

P6M past 6 months, Tas $P$ treatment as prevention, PreP Pre-exposure Prophylatic, nPEP Post-exposure prophylactic, STI Sexually Transmitted Infection, HIV Human Immunodeficiency Virus, GP General Practioner

${ }^{a}$ Only asked to those that reported having a GP

significantly lower HIV treatment optimism (mean score: 24 versus $26 ; p<0.001)$.

Table 2 presents unadjusted and adjusted generalized linear mixed models for comparisons between younger and older GBM. After controlling for gender identification, sexual orientation, HIV status, and income, consistent condom use as an HIV prevention strategy $(\mathrm{aOR}=$ $1.45,95 \% \mathrm{CI}=1.07-1.98$ ), and reporting sex/escort work in the past 6 months $(\mathrm{aOR}=2.64,95 \% \mathrm{CI}=1.32-5.27)$ were positively associated with younger age. Having a $\mathrm{GP}(\mathrm{aOR}=0.25,95 \% \mathrm{CI}=0.15-0.41)$ was negatively associated with younger age. Among GBM who had a GP, participants who have not disclosed their sexual orientation $(\mathrm{aOR}=0.35,95 \% \mathrm{CI}=0.17-0.72)$ were more likely to be younger. Participants who have heard of PrEP (aOR $=0.43,95 \% \mathrm{CI}=0.31-0.59)$ and PEP $(\mathrm{aOR}=0.53$, 95\%CI $=0.36-0.77$ ), and had higher HIV treatment optimism scores $(\mathrm{aOR}=0.93,95 \% \mathrm{CI}=0.90-0.96$; per 1 point scale increase), were less likely to be young.

Table 3 presents a sub-analysis of participants aged $<35$ years at baseline $(n=246,35.2 \%$ of the entire sample) who were indicated at 889 study visits about whether or not they had ever or recently participated in either of the two Vancouver-based leadership programs. Fifty participants $(20.3 \%$ of age sub-sample) reported ever or recently participating. Percentages reported in Table 3 show a visit-level comparison between visits where YGBM indicated program participation and all visits where no participation was recorded. Those that reported ever participating in a leadership program were significantly more likely to have used serosorting as an HIV prevention strategy in the P6M (OR $=1.55,95 \% \mathrm{CI}=1.03-2.35)$, to have heard of PrEP $(\mathrm{OR}=2.19,95 \% \mathrm{CI}=1.12-4.29)$, to have heard of PEP (OR $=2.89,95 \% \mathrm{CI}=1.20-6.92)$, and to have higher HIV treatment optimism scores $(\mathrm{OR}=1.06$ per 1 score increase, $95 \% \mathrm{CI}=1.01-1.12)$. The interaction between HIV status and any condomless anal sex with an opposite/unknown status partner in the P6M (CAS) was significant with respect to leadership program attendance; there was a significant association between CAS and program participation for HIV-positive GBM, and no significant difference found for HIV-negative men. HIV-positive participants who reported recent CAS were more likely to have attended an HIV leadership program compared with HIV-positive GBM who did not attend leadership programs $(\mathrm{aOR}=0.14$, $95 \% \mathrm{CI}=0.03-0.61$ ); there was no significant difference for HIV-negative participants in CAS between leadership program attendance or not $(\mathrm{aOR}=0.90,95 \% \mathrm{CI}=0.43-1.87$; aOR ratio $=0.16,95 \% \mathrm{CI}=0.03-0.80)($ Fig. 1$)$.

\section{Discussion}

GBM in our study who reported consistent condom use and were less likely to use HIV seroadaptive preventive practices such as serosorting and viral load sorting were more likely to be young. Participants less aware of biomedical HIV prevention strategies such as PrEP and had less HIV treatment optimism were also more likely to be younger. GBM without a GP, and among those who had a GP but were not 'out' to their GPs were also more likely to be young. Approximately 1 in five YGBM had participated in youth-led HIV prevention leadership programming such as MpowermentYVR or Totally Outright in Vancouver. YGBM who participated in these programs were significantly more likely to be aware of PrEP and PEP, and had higher HIV treatment optimism. Moreover, only among YGBM living with HIV did we find that HIV leadership programs attendance was associated with lower odds of condomless anal sex with serodiscordant or unknown HIV status partner. YGBM living with HIV face unique challenges navigating their sexual lives compared with HIV-negative youth peers, and may be choosing to employ serosorting or avoid anal sex altogether.

Despite previous studies in the US highlighting increased condomless sex among YGBM [27], encouragingly we found that $68 \%$ of YGBM in Momentum reported using consistent condom use as an HIV prevention strategy, which was significantly higher than older GBM in this study (45.6\%). Condom use promotion continues to be a key message in sexual education for young people, including YGBM, which may help explain why condom use seems to have been embraced by our younger participants [28].

Reduced PrEP and PEP awareness among YGBM in our study is an important finding given that previous work highlighted that YGBM in Vancouver who were less aware of PrEP were HIV-negative, had poorer access to condoms, and preferred receptive anal sex, indicating multiple factors for increased HIV acquisition [29]. Attending HIV leadership programming ameliorated YGBM's awareness disparities with respect to PrEP and PEP. In our sub-analysis, YGBM who attended youth-led HIV leadership and prevention programs were 
Table 2 Unadjusted and adjusted odd ratios for differences between youth and adult GBM $(n=698)$

\begin{tabular}{|c|c|c|}
\hline & $\begin{array}{l}\text { Unadjusted } \\
\text { Odds Ratio (OR) } \\
(95 \% \mathrm{Cl})\end{array}$ & $\begin{array}{l}\text { Adjusted Odds } \\
\text { Ratio (aOR) } \\
(95 \% \mathrm{Cl})\end{array}$ \\
\hline \multicolumn{3}{|l|}{ Demographics } \\
\hline \multicolumn{3}{|l|}{ Gender Identity } \\
\hline Male & 1.00 & 1.00 \\
\hline Trans-man/Intersex & $5.12(1.93-13.62)$ & $3.33(1.14-9.74)$ \\
\hline \multicolumn{3}{|l|}{ Ethnicity } \\
\hline White & 1.00 & 1.00 \\
\hline Asian & $0.74(0.30-1.85)$ & $0.75(0.31-1.83)$ \\
\hline Indigenous & $0.26(0.06-1.10)$ & $0.19(0.04-0.84)$ \\
\hline Other & $0.83(0.31-2.23)$ & $0.67(0.24-1.87)$ \\
\hline \multicolumn{3}{|l|}{ Sexual Orientation } \\
\hline Gay & 1.00 & 1.00 \\
\hline Bisexual & $0.86(0.40-1.83)$ & $0.71(0.31-1.60)$ \\
\hline Other & $2.24(1.24-4.04)$ & $1.52(0.83-2.80)$ \\
\hline \multicolumn{3}{|l|}{ HIV Status } \\
\hline Negative & 1.00 & 1.00 \\
\hline Positive & $0.03(0.01-0.06)$ & $0.02(0.01-0.04)$ \\
\hline \multicolumn{3}{|l|}{ Annual Income } \\
\hline$<\$ 30,000$ & 1.00 & 1.00 \\
\hline$\$ 30,000-\$ 59,999$ & $0.45(0.31-0.66)$ & $0.34(0.23-0.50)$ \\
\hline$\$ 60,000$ or more & $0.10(0.05-0.20)$ & $0.06(0.03-0.12)$ \\
\hline \multicolumn{3}{|l|}{ Behavior } \\
\hline $\begin{array}{l}\text { Recent Male Sex Partners, P6M: } \\
\text { per } 10 \text { units increase }\end{array}$ & $0.98(0.95-1.02)$ & $1.00(0.97-1.04)$ \\
\hline \multicolumn{3}{|l|}{ Sexual Risk, P6M } \\
\hline No anal sex & $0.65(0.43-0.99)$ & $0.61(0.39-0.97)$ \\
\hline $\begin{array}{l}\text { Only condom-protected } \\
\text { anal intercourse }\end{array}$ & 1.00 & 1.00 \\
\hline $\begin{array}{l}\text { Any condomless anal sex, } \\
\text { but only seroconcordant }\end{array}$ & $1.02(0.72-1.44)$ & $1.25(0.83-1.87)$ \\
\hline $\begin{array}{l}\text { Any serodiscordant } \\
\text { condomless anal sex }\end{array}$ & $0.59(0.42-0.83)$ & $0.73(0.50-1.08)$ \\
\hline \multicolumn{3}{|l|}{ Injection drug use, P6M } \\
\hline No & 1.00 & 1.00 \\
\hline Yes & $0.53(0.31-0.92)$ & $0.79(0.41-1.53)$ \\
\hline \multicolumn{3}{|l|}{ Any Escort/Sex Work } \\
\hline No & 1.00 & 1.00 \\
\hline Yes, in P6M & $2.31(1.28-4.18)$ & $2.64(1.32-5.27)$ \\
\hline Yes, but not in the P6M & $1.55(0.67-3.56)$ & $1.80(0.70-4.66)$ \\
\hline \multicolumn{3}{|c|}{ Prevention Practice, P6M: Consistent Condom Use } \\
\hline No & 1.00 & 1.00 \\
\hline Yes & $1.82(1.35-2.46)$ & $1.45(1.07-1.98)$ \\
\hline
\end{tabular}

Table 2 Unadjusted and adjusted odd ratios for differences between youth and adult GBM $(n=698)$ (Continued)

\begin{tabular}{|c|c|c|}
\hline & $\begin{array}{l}\text { Unadjusted } \\
\text { Odds Ratio (OR) } \\
(95 \% \mathrm{Cl})\end{array}$ & $\begin{array}{l}\text { Adjusted Odds } \\
\text { Ratio (aOR) } \\
(95 \% \mathrm{Cl})\end{array}$ \\
\hline \multicolumn{3}{|c|}{ Prevention Practice, P6M: Sero- positioning } \\
\hline No & 1.00 & 1.00 \\
\hline Yes & $0.53(0.37-0.76)$ & $0.55(0.37-0.81)$ \\
\hline \multicolumn{3}{|c|}{ Prevention Practice, P6M: Viral Load Sorting } \\
\hline No & 1.00 & 1.00 \\
\hline Yes & $0.44(0.27-0.71)$ & $0.75(0.44-1.26)$ \\
\hline \multicolumn{3}{|l|}{ Ever heard of PrEP } \\
\hline No & 1.00 & 1.00 \\
\hline Yes & $0.35(0.27-0.46)$ & $0.43(0.31-0.59)$ \\
\hline \multicolumn{3}{|l|}{ Ever heard of nPEP } \\
\hline No & 1.00 & 1.00 \\
\hline Yes & $0.44(0.32-0.62)$ & $0.53(0.36-0.77)$ \\
\hline $\begin{array}{l}\text { HIV Treatment Optimism Scale } \\
\text { Score per one score increase }\end{array}$ & $0.89(0.86-0.91)$ & $0.93(0.90-0.96)$ \\
\hline \multicolumn{3}{|l|}{ Health Care } \\
\hline \multicolumn{3}{|l|}{ Have a GP } \\
\hline No & 1.00 & 1.00 \\
\hline Yes & $0.13(0.08-0.22)$ & $0.25(0.15-0.41)$ \\
\hline \multicolumn{3}{|l|}{ "Out" to GPa } \\
\hline No & 1.00 & 1.00 \\
\hline Yes & $0.14(0.07-0.28)$ & $0.35(0.17-0.72)$ \\
\hline
\end{tabular}

Models adjusted for gender, sexual orientation, HIV status, and income P6M past 6 months, Tas $P$ treatment as prevention, PreP Pre-exposure Prophylactic, nPEP Post-exposure prophylactic, STI Sexually Transmitted Infection, HIV Human Immunodeficiency Virus, GP General Practitioner ${ }^{a}$ Only asked to those that reported having a GP

Bold are statistically significant $p<0.05$

significantly more likely to be aware of PrEP and PEP than those who did not attend. Previous studies have examined the impact of Mpowerment, highlighting that program attendance has been associated with increased condom use [20]. To our knowledge this was the first study to look at HIV leadership programming attendance and PrEP or PEP awareness. Our findings highlight that spaces and programming that are run by, with, and for youth may be more accessible and beneficial for YGBM. There is a need for these programs to be sustained and expanded in order to reach more YGBM. In addition to PrEP, YGBM living with HIV would especially benefit from additional education and support around newer biomedical advancements like $\mathrm{U}=\mathrm{U}[6]$.

Young adulthood is often a life stage in which individuals are at their healthiest $[30,31]$. Moreover, there are few resources for youth specific health care delivery [32, 33]. In the current study, we found that only half of YGBM had a GP, which is lower than the national average of youth accessing primary care in Canada [34] and 
Table 3 Socio-demographic, sexual health attitudes and practices, and sexual behavior characteristics between youth (aged 18 to 30 at baseline participating and not participating in youth-oriented HIV leadership programs in Vancouver, BC ( $n=246 ; 889$ visits)

\begin{tabular}{lll}
\hline Characteristics & $\begin{array}{l}\text { Use of youth } \\
\text { leadership } \\
\text { programming } \\
\text { (at each visit)? }\end{array}$ & $\begin{array}{l}\text { Unadjusted Odds } \\
\text { Ratio (OR) and }\end{array}$ \\
\cline { 2 - 3 } No $(n=717)$ & Yes $(n=172)$ & \\
& Interval (Cl)
\end{tabular}

Demographics

Gender Identity

$\begin{array}{llll}\text { Male } & 672(93.7) & 168(97.7) & 1.00 \\ \text { Trans-man/Intersex } & 45(6.3) & 4(2.3) & 0.38(0.03-5.37)\end{array}$

Ethnicity

White

Asian

$515(71.8)$

$130(75.6)$

1.00

Indigenous

Other

$97(13.5)$

18 (10.5)

$0.74(0.24-2.29)$

Sexual orientation

Gay

Bisexual

Other

HIV status

HIV Negative

HIV Positive

Annual income

Less than $\$ 30,000$

$\$ 30,000$ to $\$ 59,999$

$\$ 60,000$ and more

$36(5.0)$

$14(8.1)$

$69(9.6)$

105.8

$1.54(0.39-6.05)$

$0.57(0.13-2.47)$

$598(83.4) \quad 141(82.0) \quad 1.00$

$42(5.9) \quad 4(2.3)$

$0.51(0.10-2.49)$

$77(10.7)$

27 (15.7)

$1.74(0.57-5.37)$

Behavior

Sexual Risk, P6M

No anal sex

Only condomprotected anal intercourse

Any condomless anal sex, but only seroconcordant

Any serodiscordant $233(32.9) \quad 41(23.8) \quad 0.69(0.35-1.34)$ condomless anal sex

$640(89.3) \quad 162(94.2) \quad 1.00$

$77(10.7) \quad 10(5.8)$

$0.41(0.06-2.63)$

Any escort/sex work

$\begin{array}{llll}\text { No } & 695(96.9) & 158(91.9) & 1.00 \\ \text { Yes P6M } & 22(3.1) & 14(8.1) & 2.62(0.80-8.61) \\ \text { Yes but not P6M } & 0(0.00) & 0(0.00) & -\end{array}$

Prevention Practice P6M: Consistent condom use

$\begin{array}{llll}\text { No } & 278(39.0) & 70(40.9) & 1.00 \\ \text { Yes } & 435(61.0) & 101(59.1) & 0.89(0.59-1.34)\end{array}$

Table 3 Socio-demographic, sexual health attitudes and practices, and sexual behavior characteristics between youth (aged 18 to 30 at baseline participating and not participating in youth-oriented HIV leadership programs in Vancouver, BC ( $n=246 ; 889$ visits) (Continued)

\begin{tabular}{|c|c|c|c|}
\hline \multirow[t]{3}{*}{ Characteristics } & \multicolumn{2}{|c|}{$\begin{array}{l}\text { Use of youth } \\
\text { leadership } \\
\text { programming } \\
\text { (at each visit)? }\end{array}$} & \multirow[t]{3}{*}{$\begin{array}{l}\text { Unadjusted Odds } \\
\text { Ratio (OR) and } \\
95 \% \text { Confidence } \\
\text { Interval (Cl) }\end{array}$} \\
\hline & No $(n=717)$ & Yes $(n=172)$ & \\
\hline & $\mathrm{N}(\%)$ & (\%) & \\
\hline \multicolumn{4}{|c|}{ Prevention Practice P6M: Seropositioning } \\
\hline No & $512(71.8)$ & $128(74.9)$ & 1.00 \\
\hline Yes & $201(28.2)$ & $43(25.1)$ & $0.95(0.54-1.67)$ \\
\hline \multicolumn{4}{|c|}{ Prevention Practice P6M: Serosorting } \\
\hline No & $406(56.9)$ & $72(42.1)$ & 1.00 \\
\hline Yes & $307(43.1)$ & 99 (57.9) & $1.55(1.03-2.35)$ \\
\hline \multicolumn{4}{|c|}{ Prevention Practice P6M: Viral load sorting } \\
\hline No & $587(82.3)$ & $148(86.6)$ & 1.00 \\
\hline Yes & $126(17.7)$ & $23(13.5)$ & $0.68(0.32-1.44)$ \\
\hline
\end{tabular}

Prevention Practice P6M: Ask partner their HIV status

$\begin{array}{llll}\text { No } & 243(34.1) & 70(40.9) & 1.00 \\ \text { Yes } & 470(65.9) & 101(59.1) & 0.79(0.52-1.21)\end{array}$

Attitudes and awareness

Ever heard of PrEP

$\begin{array}{llll}\text { No } & 131(18.3) & 18(10.5) & 1.00 \\ \text { Yes } & 586(81.7) & 154(89.5) & \mathbf{2 . 1 9}(\mathbf{1 . 1 2 - 4 . 2 9 )}\end{array}$

Ever heard of nPEP

$\begin{array}{llll}\text { No } & 96(13.4) & 7(4.1) & 1.00\end{array}$

$\begin{array}{llll}\text { Yes } & 621(86.6) & 165(95.9) & \mathbf{2 . 8 9}(\mathbf{1 . 2 0} \mathbf{2 0 . 9 2 )}\end{array}$

HIV Treatment $\quad 27$ (24-31) $28(25-30) \quad \mathbf{1 . 0 6}(\mathbf{1 . 0 1 - 1 . 1 2 )}$

Optimism Scale

Score per one score

increase

Health Care

Have a GP

$\begin{array}{llll}\text { No } & 271(38.3) & 81(48.2) & 1.00 \\ \text { Yes } & 437(61.7) & 87(51.8) & 0.71(0.33-1.53) \\ \text { Out to GP } & & & \\ \text { No } & 87(19.9) & 29(33.3) & 1.00 \\ \text { Yes } & 350(80.1) & 58(66.7) & 0.51(0.13-2.06)\end{array}$

Ever HPV vaccination

\begin{tabular}{llll} 
No & $693(98.4)$ & $162(96.4)$ & 1.00 \\
Yes & $11(1.6)$ & $6(3.6)$ & $1.48(0.57-3.83)$ \\
\hline
\end{tabular}

Bold are significant at $p<0.05$

significantly lower than older GBM in our study. This indicates a structural barrier for YGBM to access biomedical treatment and prevention options from a physician. Previous Canadian research has highlighted that 


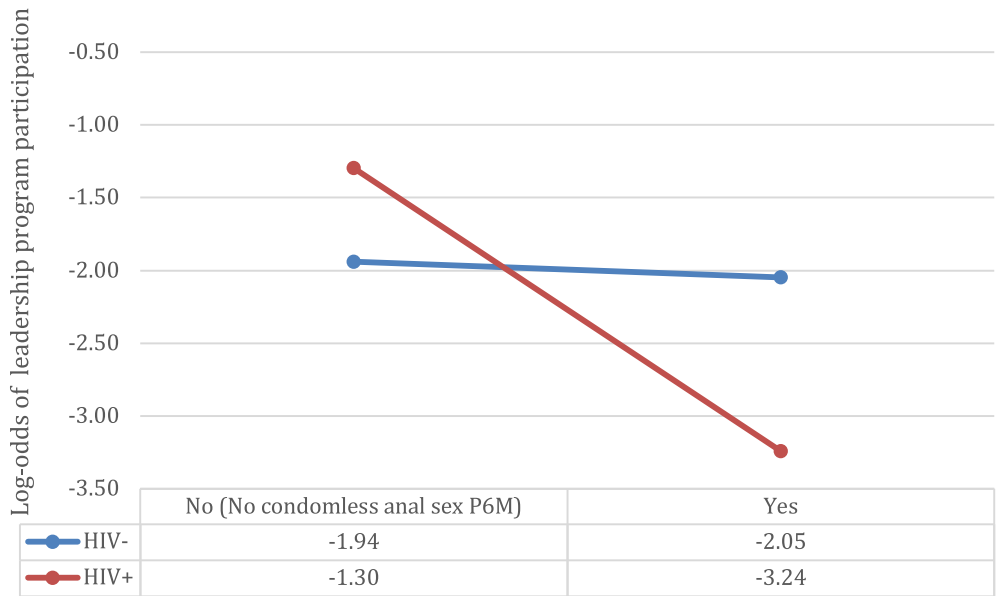

Fig. 1 Interaction between HIV status and any recent condomless anal sex with a serodiscordant or unknown status partner (yes) versus none on the outcome of HIV leadership program attendance

young adults (18-30) have a higher proportion of unmet health needs largely due to the inability to attain a primary care provider who is accepting new patients [35]. Younger individuals are less likely to seek primary care in general, and in Canada there is a large shortage of doctors accepting new patients. Moreover, many YGBM in Vancouver may have recently moved to the city from other parts of Canada or immigrated from other countries [36].

Beyond the systematic lack of access to GPs, we found that YGBM with GPs were less likely to be out to their GPs. Previous research among GBM in Vancouver has found that GBM who did not disclose their sexual orientation and/or practices were less likely to have been tested for HIV [37]. YGBM may choose to not disclose their sexual health behaviours to their physicians for numerous reasons. YGBM who may be less likely to access primary health care and be out to health providers due to stigma and discrimination and may not feel comfortable discussing sexual health concerns with their primary health care provider [38]. Moreover, primary care providers themselves may not feel comfortable discussing sexual health concerns with their patients [39]. Experiencing heteronormative assumptions within healthcare settings where GBM seek sexual health services profoundly influences young men's experiences of these services [38].

These findings have important implications for health care and education systems. Positively, findings surrounding consistent condom use indicate that many YGBM are taking precaution to reduce passing HIV and other STIs to their partners. However, critical disparities in HIV prevention awareness and access to primary health care that is culturally competent in terms of sexuality remain. Health service delivery should consider implementing youth- and LGBTQ-friendly sexual health spaces in which appropriate sexual healthcare and education can be delivered to YGBM in an effort to reduce HIV transmission at younger ages. Moreover, low PrEP awareness and HIV treatment optimism among YGBM should be addressed through increased relevant and comprehensive sexual education in schools that is grounded in the lived realities of YGBM [40]. Youth, regardless of sexual orientation, can benefit from increased knowledge and awareness of the different HIV prevention tools and resources that are available to them and their peers [1]. Moreover, to ensure sexual health literacy begins early, youth-friendly and inclusive spaces for sexual health should be included in the classroom. In order to improve inclusivity, there is a need to reform health care service delivery and sexual health education that is often heteronormative [38]. One way in which to facilitate improved acceptability and access for YGBM would be to cultivate professional allies in health care and educational settings [41]. While these systems changes are being implemented, investing in youth-led programming outside of formal health care and educational settings is essential to promote sexual health for YGBM.

\section{Strengths and limitations}

The use of RDS-sampling within our study allowed for a more diverse, if not representative, cohort of GBM in a setting where HIV treatment is available at no cost [42, 43]. While our sub-analysis of YGBM attending leadership programs had limited statistical power, it leveraged a population-based cohort to provide external empirical evidence as to some of the impacts of these programs. Due to small counts in many of the ethnicity groups within this study we were unable to meaningfully discuss the realities of YGBM of colour. We acknowledge that there is a need for increased research to focus on the needs and strengths of GBM who are Indigenous and/or of colour 
internationally and in Canada. The observational design provides a real-world perspective of effectiveness, although cannot produce the specific efficacy data that randomized trials would yield. Given the positive impact on PrEP and PEP awareness among those YGBM who attended leadership programming, future studies with different designs and sampling should further examine the impact of participation in these programs.

\section{Conclusion}

Our study highlights that participants that had less awareness of new prevention technologies tended to be younger than those who had higher awareness. However, participation in GBM-led HIV leadership programs was associated with increased HIV-prevention knowledge and treatment optimism. Findings suggest that given limited access to primary care alongside potentially inadequate comprehensive sexual health education, community-led and youth-friendly sexual health programming are beneficial for improving YGBM's awareness of different HIV prevention mechanisms. Efforts need to continue to work with YGBM to address gaps in sexual health education in schools, and to explore ways in which school- and community-level programming can increase sexual health literacy as well as access to and uptake of necessary HIV prevention resources.

\section{Acknowledgements}

The authors would like to thank the Momentum Health Study participants, office staff, and community advisory board, as well as our community partner agencies, Health Initiative for Men, YouthCO HIV \& Hep C Society, and Positive Living Society of BC.

\section{Funding}

Momentum is funded through the National Institute on Drug Abuse (R01DA031055-01A1) and the Canadian Institutes for Health Research (MOP-107544, FDN-143342, PJT-153139). KC is supported by the Vanier Canadian Graduate Scholarship funded by the Canadian Institutes of Health Research. DMM and NJL are supported by Scholar Awards from the Michael Smith Foundation for Health Research (\#5209, \#16863). HLA is supported by a Postdoctoral Fellowship Award from the Canadian Institutes of Health Research (Grant \# MFE-152443). The funding bodies had no role in data collection, analysis, interpretation, the design of the study, or the writing of the manuscript.

\section{Availability of data and materials}

For information about access to the study data, please contact Dr. David M. Moore (dmoore@cfenet.ubc.ca), Dr. Nathan Lachowsky (nlachowsky@cfenet. ubc.ca), or Dr. Robert S. Hogg (bob.hogg@cfenet.ubc.ca), Principle Investigators of the Momentum Study.

\section{Authors' contributions}

$\mathrm{KC}$ and NJL designed the research question and drafted the initial manuscript. Data analyses were performed by NB and LW. HLA provided analytic guidance, support and significantly contributed to drafting and revising the manuscript. $\mathrm{SC}, \mathrm{DH}$, and JJ contributed to the analysis design, interpretation of the data, and provided substantive revisions to the manuscript. DMM, NJL, RSH, EAR, and GO made significant contributions to the conception of the study and provided substantive revisions on the manuscript. All authors contributed to the interpretation of the data, provided editorial feedback, and read and approved the final manuscript.

\section{Ethics approval and consent to participate}

Ethics approval for this study was granted by the research ethics boards of The University of British Columbia-Providence Health Care Research Unit, The University of Victoria, and Simon Fraser University, research ethics approval number (H11-00691). Written informed consent was obtained from all participants prior to participation.

\section{Consent for publication}

Not applicable.

\section{Competing interests}

The authors declare that they have no competing interests.

\section{Publisher's Note}

Springer Nature remains neutral with regard to jurisdictional claims in published maps and institutional affiliations.

\section{Author details}

'British Columbia Centre for Excellence in HIV/AIDS, 608-1081 Burrard St, Vancouver, BC V6Z 1Y6, Canada. ${ }^{2}$ School of Population and Public Health, University of British Columbia, 2206 East Mall, Vancouver, BC V6T 1Z3, Canada. ${ }^{3}$ YouthCO HIV \& Hep C Society, 205-568 Seymour St., Vancouver, BC V6B 3J5, Canada. ${ }^{4}$ Faculty of Medicine, University of British Columbia, 317-2194 Health Sciences Mall, Vancouver, BC V6T 1Z3, Canada.

${ }^{5}$ Community-Based Research Centre for Gay Men's Health, 1007-808 Nelson St., Vancouver, BC V6Z 2H2, Canada. ${ }^{6}$ Department of Anthropology, University of Victoria, Cornett Building B228, 3800 Finnerty Road, Victoria, BC V8P 5C2, Canada. ${ }^{7}$ Faculty of Health Sciences, Simon Fraser University, 8888 University Drive, Burnaby, BC V5A 156, Canada. ${ }^{8}$ School of Public Health and Social Policy, University of Victoria, Human and Social Development Building B202, 3800 Finnerty Road, Victoria, BC V8P 5C2, Canada.

Received: 28 November 2018 Accepted: 3 April 2019

Published online: 24 April 2019

\section{References}

1. Beyrer C, Baral SD, van Griensven F, Goodreau SM, Chariyalertsak S, Wirtz AL, Brookmeyer R. Global epidemiology of HIV infection in men who have sex with men. Lancet. 2012;380(9839):367-77.

2. Bourgeois AC, Edmunds M, Awan A, Jonah A, Varsaneaux O, Siu W. In: Rep CCD, editor. HIV in Canada- Surveillance Report, 2016, vol. 43; 2017.

3. Bourgeois AC, Edmunds M, Awan A, Jonah L, Varsaneux O, Siu W. HIV in Canada_Surveillance Report, 2016. Can Commun Dis Rep. 2017;43(12):248-56.

4. Sullivan PS, Carballo-Diéguez A, Coates T, Goodreau SM, McGowan I, Sanders EJ, Smith A, Goswami P, Sanchez J. Successes and challenges of HIV prevention in men who have sex with men. Lancet. 2012;380(9839):388-99.

5. Rotheram-Borus MJ, Davis E, Rezai R. Stopping the rise of HIV among adolescents globally. Curr Opin Pediatr. 2018;30(1):131-6.

6. Coates TJ, Richter L, Caceres C. Behavioural strategies to reduce HIV transmission: how to make them work better. Lancet. 2008;372(9639):669-84

7. Pettifor A, Nguyen NL, Celum C, Cowan FM, Go V, Hightow-Weidman L. Tailored combination prevention packages and PrEP for young key populations. J Int AIDS Soc. 2015;18(2 Suppl 1):19434.

8. Pachankis JE, Hatzenbuehler ML, Hickson F, Weatherburn P, Berg RC, Marcus U, Schmidt AJ. Hidden from health: structural stigma, sexual orientation concealment, and HIV across 38 countries in the European MSM Internet Survey. AIDS. 2015;29(10):1239-46.

9. Mayer KH, Wheeler DP, Bekker LG, Grinsztejn B, Remien RH, Sandfort TG, Beyrer C. Overcoming biological, behavioral, and structural vulnerabilities: new directions in research to decrease HIV transmission in men who have sex with men. J Acquir Immune Defic Syndr. 2013;63(Suppl 2):S161-7.

10. Knight R, Small W, Shoveller JA. HIV stigma and the experiences of young men with voluntary and routine HIV testing. Sociol Health IIIn. 2016;38(1):153-67.

11. British Columbia Centre for Excellence in HIV/AIDS. Guidance for the use of Pre-exposure prophylatic (PrEP) for the prevention of HIV aquisition in British Columbia. Vancouver: University of British Columbia; 2017.

12. YouthCO. Sex Ed is our right. Vancouver: Community-bAsed Research Centre for Gay Men's Health; 2018.

13. Shipley H. Queering institutions? Sexual indentity in public education in a Canadian context. Fem Teach. 2013;23(3):196-210. 
14. Kubicek K, Beyer WJ, Weiss G, Iverson E, Kipke MD. In the dark: young men's stories of sexual initiation in the absence of relevant sexual health information. Health Educ Behav. 2010;37(2):243-63.

15. Mackellar DA, Valleroy LA, Anderson JE, Behel S, Secura GM, Bingham T, Celentano DD, Koblin BA, LaLota M, Shehan D, et al. Recent HIV testing among young men who have sex with men: correlates, contexts, and HIV seroconversion. Sex Transm Dis. 2006;33(3):183-92.

16. Margolis AD, Joseph $H$, Belcher L, Hirshfield S, Chiasson MA. 'Never testing for HIV' among men who have sex with men recruited from a sexual networking website, United States. AIDS Behav. 2012;16(1):23-9.

17. Saewyc EM, Homma Y. School safety and connectedness matter for more than educational outcomes: the link between school connectedness and adolescent health. In: Russell S, Horn S, editors. Sexual orientation, gender identity, and schooling: global perspectives on the nexus of research practice and policy. New York: Oxford University Press; 2016.

18. Veniegas RC, Kao UH, Rosales R. Adapting HIV prevention evidence-based interventions in practice settings: an interview study. Implement Sci. 2009;4:76.

19. Jeffries WL, Garrett S, Phields M, Olubajo B, Lemon E, Valdes-Salgado R, Collins CB Jr. Implementation of evidence-based HIV interventions for gay, bisexual, and other men who have sex with men. AIDS Behav. 2017;21(10): 3000-12.

20. Kegeles SM, Hays RB, Coates TJ. The Mpowerment project: a communitylevel HIV prevention intervention for young gay men. Am J Public Health. 1996;86(8):1129-36.

21. Kwang M. Totally Outright for facilitators. Vancouver: Community based research centre; 2007.

22. Moore DM, Cui Z, Lachowsky N, Raymond HF, Roth E, Rich A, Sereda P, Howard T, McFarland W, Lal A, et al. HIV community viral load and factors associated with elevated viremia among a community-based sample of men who have sex with men (MSM) in Vancouver, Canada. J Acquir Immune Defic Syndr. 2016;72(1):87-95.

23. BC Centre for Disease Control. STI certified practice online course British Columbia: Provincial Health Services Authority; 2019

24. Kingdon MJ, Storholm ED, Halkitis PN, Jones DC, Moeller RW, Siconolfi D, Solomon TM. Targeting HIV prevention messaging to a new generation of gay, bisexual, and other young men who have sex with men. J Health Commun. 2013;18(3):325-42.

25. The Commonwealth. Youth: Commonwealth Secretariat; 2018. Available from: http://thecommonwealth.org/youth. Accessed 16 July 2018.

26. Van de Ven P, Crawford J, Kippax S, Knox S, Prestage G. A scale of optimismscepticism in the context of HIV treatments. AIDS Care. 2000;12(2):171-6.

27. Paz-Bailey G, Mendoza MC, Finlayson T, Wejnert C, Le B, Rose C, Raymond HF, Prejean J, Group NS. Trends in condom use among MSM in the United States: the role of antiretroviral therapy and seroadaptive strategies. AIDS. 2016;30(12):1985-90.

28. Budhwani H, Hearld KR, Barrow G, Peterson SN, Walton-Levermore K. A comparison of younger and older men who have sex with men using data from Jamaica AIDS support for life: characteristics associated with HIV status. Int J STD AIDS. 2016;27(9):769-75.

29. Lachowsky NJ, Lin SY, Hull MW, Cui Z, Sereda P, Jollimore J, Rich A, Montaner JS, Roth EA, Hogg RS, et al. Pre-exposure prophylaxis awareness among gay and other men who have sex with men in Vancouver, British Columbia, Canada. AIDS Behav. 2016;20(7):1408-22.

30. Resnick MD, Catalano RF, Sawyer SM, Viner R, Patton GC. Seizing the opportunities of adolescent health. Lancet. 2012;379(9826):1564-7.

31. Viner RM, Ozer EM, Denny S, Marmot M, Resnick M, Fatusi A, Currie C. Adolescence and the social determinants of health. Lancet. 2012;379(9826): 1641-52.

32. Tepper V, Zaner S, Ryscavage P. HIV healthcare transition outcomes among youth in North America and Europe: a review. J Int AIDS Soc. 2017;20(Suppl $3: 21490$.

33. Geary RS, Webb EL, Clarke L, Norris SA. Evaluating youth-friendly health services: young people's perspectives from a simulated client study in urban South Africa. Glob Health Action. 2015;8:26080.

34. Guttman A, Gandhi S, Hanvey LP, Barwick M, Cohen E, Glazer S, Reisman J, Brownell M. Primary health care services for children and youth in Canada: access, quality and structure. In: The Health of Canada's Children and Youth: A CICH Profile. Ottawa: Canadian Institutes for Health Research; 2017.

35. Marshall EG. Do young adults have unmet healthcare needs? J Adolesc Health. 2011:49(5):490-7.
36. Community Based Research Centre for Gay Men's Health (CBRC). Gay generations: life course and gay men's health. In: Findings from the nationa sex now survey. Vancouver: Community Based Research Centre for Gay Men's Health (CBRC); 2016.

37. Ng BE, Moore D, Michelow W, Hogg R, Gustafson R, Robert W, Kanters S, Thumath M, McGuire M, Gilbert M. Relationship between disclosure of same-sex sexual activity to providers, HIV diagnosis and sexual health services for men who have sex with men in Vancouver, Canada. Can J Public Health. 2014;105(3):e186-91.

38. Knight R, Shoveller JA, Oliffe JL, Gilbert M, Goldenberg S. Heteronormativity hurts everyone: experiences of young men and clinicians with sexually transmitted infection/HIV testing in British Columbia, Canada. Health (London). 2013;17(5):441-59.

39. Gott M, Galena E, HInchliff S, Elford H. "Opening a can of worms": GP and practice nurse barriers to talking about sexual health in primary care. Fam Pract. 2004;21:528-36.

40. Harper GW. Sex isn't that simple: culture and context in HIV prevention interventions for gay and bisexual male adolescents. Am Psychol. 2007;62(8): 803-19.

41. Craig SL, Doiron C, Dillon F. Cultivating professional allies for sexual minority youth: a community-based educational intervention. J Homosex. 2015; 62(12):1703-21.

42. Lachowsky NJ, Lal A, Forrest JI, Card KG, Cui Z, Sereda P, Rich A, Raymond HF, Roth EA, Moore DM, et al. Including online-recruited seeds: a respondent-driven sample of men who have sex with men. J Med Internet Res. 2016;18(3):e51.

43. Forrest JI, Lachowsky NJ, Lal A, Cui Z, Sereda P, Raymond HF, Ogilvie G, Roth EA, Moore D, Hogg RS. Factors associated with productive recruiting in a respondent-driven sample of men who have sex with men in Vancouver, Canada. J Urban Health. 2016;93(2):379-87.

Ready to submit your research? Choose BMC and benefit from

- fast, convenient online submission

- thorough peer review by experienced researchers in your field

- rapid publication on acceptance

- support for research data, including large and complex data types

- gold Open Access which fosters wider collaboration and increased citations

- maximum visibility for your research: over $100 \mathrm{M}$ website views per year

At BMC, research is always in progress.

Learn more biomedcentral.com/submissions 